\title{
Median Mononeuropathy Among Active Workers: Are There Differences Between Symptomatic and Asymptomatic Workers?
}

\author{
Robert A. Werner, MD, 1,2,3* Alfred Franzblau, MD, ${ }^{3}$ James W. Albers, MD, PhD, 1,3,4 \\ and Thomas J. Armstrong, PhD $^{3}$
}

The objective was to determine whether symptomatic workers with an abnormal sensory nerve conduction study consistent with carpal tunnel syndrome differed, in terms of electrophysiologic measures, psychosocial, demographic, anthropometric, or ergonomic variables, from workers with an asymptomatic median mononeuropathy.

This was a cross-sectional study of active workers at six different work sites. Cases were defined as workers with electrodiagnostic findings of a median mononeuropathy in either hand, based on a 0.5-msec prolongation of the median sensory evoked peak latency compared to the ulnar latency. This group was stratified on the basis of symptoms of numbness, tingling, burning or pain in the hand. The two groups were compared in terms of demographic, anthropomorphic, psychosocial. electrophysiologic, and ergonomic risk factors.

Active workers from six different sites were tested; five sites involved manufacturing workers, and one site represented clerical workers. One hundred eighty-four active workers with a median mononeuropathy were documented on nerve conduction studies. These workers represented a subset of more than 700 workers screened at six different locations.

The main outcome measure was the patient's report of symptoms of pain, numbness, tingling or burning in the hand or fingers that lasted more than 1 week or occurred three or more times at the initial screening.

Workers with a median mononeuropathy who complained of hand symptoms were more likely to be female, to have jobs with higher hand repetition levels, to have higher ratings of job security, not to have a history of diabetes, to use more force in their job with more abnormal postures of their wrist and fingers, and to have a trend toward a more prolonged median sensory distal latency. Most logistic regression models explained less than $15 \%$ of the variance (pseudo $R^{2}$ ).

Women with jobs that have higher ergonomic risks and no history of diabetes were more likely to have reported symptoms associated with carpal tunnel syndrome compared to other workers with a documented median mononeuropathy. Psychosocial variables were not particularly discriminatory. None of the models allows enough precision to predict on an individual basis. Am. J. Ind. Med. 33:374-378, 1998. @ 1998 Wiley-Liss, Inc.

KEY WORDS: median nerve; carpal tunnel syndrome; electromyography; occupational medicine

\footnotetext{
${ }^{1}$ Department of Physical Medicine and Rehabilitation, University of Michigan Medical Center, Ann Arbor, Michigan

2Physical Medicine and Rehabilitation Service, Veterans Affairs Medical Center, Ann Arbor, Michigan

${ }^{3}$ Department of Environmental and Industrial Health, School of Public Health, University of Michigan, Ann Arbor, Michigan

${ }^{4}$ Department of Neurology, University of Michigan Medical Center, Ann Arbor, Michigan
}

Contract grant sponsor: National Institute for Occupational Safety and Health; Contract grant RO1-OH02941-01; Contract grant sponsor: National Institute for Occupational Safety and Health.

*Correspondence to: Robert A. Werner, Ann Arbor VAMC, 2215 Fuller Rd. (117), Ann Arbor, MI 48105

Accepted 21 October 1997 


\section{INTRODUCTION}

Carpal tunnel syndrome (CTS) is one of a number of muscle-, tendon-, and nerve-related disorders that afflict persons performing hand intensive work. There has been a tremendous increase in the numbers of reported cases [Franklin et al., 1991; Hanrahan et al., 1991; Stock, 1991]. In previous studies, Franzblau et al. [1993, 1994] reported that up to $25 \%$ of active workers had a median mononeuropathy in one or both hands (an abnormal slowing of the median sensory nerve across the wrist, compared to the ulnar sensory nerve) and that this finding was consistent over several industrial sites. More than one-half of such subjects did not report any wrist, hand or finger symptoms consistent with CTS. Such a high prevalence of median mononeuropathy, many of which are asymptomatic, raises the issue of the utility and interpretation of nerve conduction studies in screening and diagnosing carpal tunnel syndrome.

We sought to investigate whether there were differences in demographics, anthropometrics, psychosocial profile, medical history, electrophysiologic measures, or ergonomic risks between those workers who reported symptoms and those who did not among all workers who had a confirmed abnormality of the median nerve in one or both wrists. We hypothesized that workers with jobs that were more repetitious in terms of hand movement, workers with lower job satisfaction and workers with more profound abnormalities of the median nerve would be more likely to complain of symptoms.

\section{MATERIAL AND METHODS}

The data were collected as part of cross-sectional studies of active workers at six different work sites. Cases for this study were defined as workers with electrodiagnostic findings of a median mononeuropathy in either hand using a comparison of median and ulnar sensory evoked peak latencies. Prolongation of the median sensory evoked response of $\geq 0.5 \mathrm{msec}$ was defined as abnormal. The 0.5msec cutoff is a standard electrodiagnostic criterion for confirming a median mononeuropathy at the wrist and is a better criterion than an absolute latency and can control for the influences of age, disease state and limb temperature [Jackson and Clifford, 1989; Kimura, 1983; Redmond and Rivner, 1988].

The sites included two automobile parts manufacturers, a furniture manufacturer, a spark plug manufacturer, a paper container manufacturer, and the clerical staff of an insurance company. There was an average participation rate of $79 \%$, with a range of 45-89\%, among eligible workers at the six study sites. Workers were selected to be representative of a range of jobs typically found in contemporary manufacturing and clerical sites. They included exposure to high-, medium-, and low-repetition manufacturing jobs and were rated on a scale of $1-10$, in terms of frequency of hand repetition, where $0=$ idle, $2=$ frequent pauses, $4=$ slow steady motion, $6=$ steady motion, $8=$ rapid steady motion, and $10=$ rapid steady motion, difficulty keeping up [Latko et al., 1997]. The jobs ranged from loading machines and monitoring their operations to highly repetitive hand transfer and assembly operations. Office jobs ranged from incidental use of keyboards to medium use in conjunction with insurance claims processing. Each job category was rated by a group of industrial engineers and hygienists on the visual analog scale noted above using a videotape of the job. Similar ratings were done of hand force as well as hand, wrist and forearm posture and contact stress. The ergonomic assessments were done at all but the first two sites and the clerical site. The symptom questionnaire identifies selfreported symptoms of numbness, tingling, burning, and pain in the wrist, hand, and fingers. The upper extremity symptom questionnaire is described in detail in other articles [Franzblau et al., 1993, 1994; Werner et al., 1997].

Subjects provided written consent as approved by our Institutional Review Board and each subject completed an initial symptoms questionnaire. Age, gender, educational level, and prior medical history were self-reported within the questionnaire. The anthropometric measures includes wrist dimensions, index finger length and circumference, height, weight, and triceps skin fold.

Psychosocial variables were assessed using a questionnaire developed by Karasek [1985]. The areas assessed included estimates of skill discretion, job insecurity, perceived stress, and job satisfaction based on the decision latitude of the worker and the psychological demands placed on the worker. Only workers at the last three sites had these variables included in the questionnaire.

Electrodiagnostic studies of the median and ulnar sensory nerves were conducted bilaterally using the techniques described by Kimura [1983]. The tests were performed using antidromic supramaximal stimulation, a distance of $14 \mathrm{~cm}$, and ring recording electrodes placed around digits 2 and 5. A standard inter-electrode distance of $3 \mathrm{~cm}$ was used. Hand temperature was recorded and the hand was warmed if the midpalmar temperature was below $32^{\circ} \mathrm{C}$. All studies were performed on-site by a board certified electromyographer and a certified electrodiagnostic technician using a TECA TD 20 (TECA, Pleasantville, NY). The peak latency and the amplitude (baseline to peak) were recorded for each sensory nerve.

\section{Statistical Evaluation}

The data were analyzed using STATA statistical software [StataCorp, 1995]. The analysis consisted of descriptive statistics of the potential differentiating variables (i.e., demographic, psychosocial, anthropometric, and electrophysiologic measures) stratified by presence of hand symp- 
TABLE I. Description of Patient Population and Percentage of Population With Abnormal Median Nerves Across the Wrist: Michigan 1994- 1996

\begin{tabular}{|c|c|c|c|c|}
\hline Site & $\begin{array}{l}\text { Type of work } \\
\text { at site }\end{array}$ & $\begin{array}{c}\text { No. of } \\
\text { workers } \\
\text { recruited }\end{array}$ & $\begin{array}{l}\text { No. (\%) } \\
\text { with } \\
\text { MM }\end{array}$ & $\begin{array}{c}\text { No. (\%) } \\
\text { with MM } \\
\text { but no } \\
\text { symptoms }\end{array}$ \\
\hline 1 & Auto parts manufacturer & 119 & $32(27 \%)$ & $8(7 \%)$ \\
\hline 2 & Furniture manufacturer & 98 & $25(26 \%)$ & $15(15 \%)$ \\
\hline 3 & Paper containers manufacturer & 77 & $26(34 \%)$ & $15(19 \%)$ \\
\hline 4 & Auto parts manufacturer & 64 & $19(30 \%)$ & $8(13 \%)$ \\
\hline 5 & Clerical insurance workers & 164 & $25(15 \%)$ & $7(4 \%)$ \\
\hline 6 & Spark plus manufacturer & $\underline{202}$ & $57(28 \%)$ & $\underline{38}(19 \%)$ \\
\hline Totals & & $\overline{724}$ & $\overline{184}(25 \%)$ & $\overline{91}(13 \%)$ \\
\hline
\end{tabular}

toms. Logistic regression models were developed using presence or absence of symptoms as the dependent variable and the variables noted above as the independent variables. A stepwise backward regression was employed. The logistic regression models that included electrophysiologic data were performed using the results in the dominant hand; cases with a median mononeuropathy in only the nondominant hand were excluded in these analyses. Analysis is reported on only those factors collected at all sites. Some of the ergonomic and psychological data are excluded, as they were not routinely collected at all sites.

\section{RESULTS}

Of the 727 workers screened at the six sites, 184 (25\% had evidence of a median mononeuropathy in at least one hand). One hundred fifty-one had a median mononeuropathy in their dominant hand, including $46 \%$ of the workers who had bilateral median mononeuropathies. Table I lists the findings by site. Fifty-one percent of the workers with a documented median mononeuropathy reported symptoms of numbness, tingling, burning, or pain in the wrist fingers or hand. The mean age of this cohort was $42 \pm 10$ years (range 25-69). Fifty-four percent of the workers were female; this was not evenly distributed across all sites. Eighty-five percent of the clerical workers were female, and less than one-half of the workers in most of the industrial sites were female. Ninety-two percent were right handed. The mean body mass index (BMI) was $30.6 \pm 6.7 \mathrm{~kg} / \mathrm{m}^{2}$, range 15.4-62.3; a BMI of $>30 \mathrm{~kg} / \mathrm{m}^{2}$ is usually classified as obese [Anderson and Rafferty, 1992]. The rating of hand repetition for the jobs screened ranged from 1 to 8.5 with a mean of $5.2 \pm 2.7$. Seventy-five percent of workers had a high school diploma or less. Only $9 \%$ had 4-year college degrees.
TABLE II. Univariate Analysis of Factors in Workers With and Without Self-reported Symptoms: Michigan 1994-1996

\begin{tabular}{|c|c|c|c|c|}
\hline Factors & $\mathrm{N}$ & $\begin{array}{l}\text { MM plus } \\
\text { symptoms }\end{array}$ & $\begin{array}{c}\text { MM } \\
\text { without } \\
\text { symptoms }\end{array}$ & $p$-value \\
\hline Age & 184 & 43.0 & 42.5 & 0.73 \\
\hline Gender (\% female) & 184 & $67 \%$ & $42 \%$ & 0.0006 \\
\hline Body mass index & 184 & 30.9 & 30.3 & 0.52 \\
\hline Triceps skin fold & 151 & 32.3 & 25.8 & 0.01 \\
\hline Wrist ratio (AP/lateral) & 184 & .722 & .717 & 0.28 \\
\hline Index finger circumference & 184 & 69.1 & 70.5 & 0.09 \\
\hline Diabetic workers & 14 & $21 \%$ & $79 \%$ & 0.02 \\
\hline More than HS diploma & 126 & $27 \%$ & $22 \%$ & 0.41 \\
\hline Social supporta & 99 & 11.5 & 11.0 & 0.31 \\
\hline J ob dissatisfactiona & 99 & .23 & .24 & 0.71 \\
\hline J ob insecuritya & 99 & 3.5 & 4.1 & 0.02 \\
\hline Perceived stress ${ }^{a}$ & 99 & 24.5 & 24.1 & 0.79 \\
\hline Repetition level & 184 & 5.8 & 4.5 & 0.002 \\
\hline Peak force & 98 & 4.6 & 4.9 & 0.33 \\
\hline Average force & 98 & 1.2 & 1.0 & 0.04 \\
\hline Finger posture & 98 & 2.5 & 2.1 & 0.01 \\
\hline Wrist posture & 98 & 7.8 & 6.9 & 0.05 \\
\hline Vibration exposure & 98 & .8 & .7 & 0.49 \\
\hline $\begin{array}{l}\text { Median sensory amplitude- } \\
\text { dominant hand }(\mu \mathrm{V})\end{array}$ & $151^{b}$ & 23.2 & 21.4 & 0.34 \\
\hline $\begin{array}{l}\text { Median sensory peak } \\
\text { latency-dominant hand } \\
\text { (msec) }\end{array}$ & $151^{b}$ & 4.1 & 4.0 & 0.48 \\
\hline $\begin{array}{l}\text { Median-ulnar sensory } \\
\text { latency-dominant hand } \\
\text { (msec) }\end{array}$ & $151^{b}$ & 1.0 & 0.9 & 0.08 \\
\hline $\begin{array}{l}\text { Bilateral median mononeu- } \\
\text { ropathies }\end{array}$ & 85 & $49 \%$ & $51 \%$ & 0.78 \\
\hline $\begin{array}{l}\text { Severe median mononeu- } \\
\text { ropathy ( } \geq 0.8 \mathrm{msec} \text { diff.) }\end{array}$ & 91 & $56 \%$ & $44 \%$ & 0.14 \\
\hline
\end{tabular}

aFrom Karasek [1985].

'Only 151 subjects had a median mononeuropathy in the dominant hand.

When stratified by presence or absence of symptoms, the two groups differed in terms of gender distribution, triceps skin folds, hand repetition level, finger and wrist posture, hand force, history of diabetes, and level of job insecurity, and there was a trend toward a prolonged relative latency of the median compared to the ulnar nerve. Table II demonstrates the mean or percentage in each group for a variety of factors and the associated $P$-value for the t-test statistic (or $\chi^{2}$ statistic for categorical data). Note that several of the factors are weighted heavily by gender, e.g., triceps skin fold and finger circumference.

Most of the psychosocial variables did not demonstrate a significant difference between the two groups. Evaluating 
workers with bilateral versus unilateral median mononeuropathies did not help differentiate which workers reported symptoms. Ergonomic factors related to repetition, finger and wrist posture, and average force applied differed significantly.

When only demographic, anthropometric, ergonomic, and electrophysiologic factors that were available for the entire sample were included, a backward stepwise logistic regression analysis resulted in a model with $P=0.004$ and a pseudo $\mathrm{R}^{2}$ of 0.14 . The significant factors in the analysis included gender (odds ratio $[\mathrm{OR}]=2.9 ; 95 \%$ confidence interval $[\mathrm{CI}]=1.5,5.8$; and repetition level $(\mathrm{OR}=1.2$; $95 \% \mathrm{CI}=1.05,1.37)$. These two factors alone accounted for $70 \%$ of the explained variance in the model.

\section{DISCUSSION}

A diagnosis of a median mononeuropathy is based solely on the electrophysiologic measures of the median relative to ulnar sensory function. This is not meant to be the equivalent of carpal tunnel syndrome with is based on the clinical history and may be confirmed by electrodiagnostic testing. Given this distinction, it is still of concern to understand why some workers with a median mononeuropathy have symptoms and some do not. This is of critical importance because nerve conduction testing is being used as a screening device to determine fitness for certain industrial jobs regardless of the presence/absence of symptoms.

One of our original hypotheses was supported; workers rated with a higher level of hand repetition were symptomatic more often than workers with a lower level of repetition. Other ergonomic factors, such as awkward wrist posture and higher forces at the hand and wrist, were also associated with more symptoms reported.

Surprisingly, our other hypotheses regarding psychosocial variables and degree of median nerve abnormalities were not well supported. Of all the psychosocial variables, only job security was significant. This relationship was opposite of what we had hypothesized; workers with more perceived job security were more likely to report symptoms associated with their median mononeuropathy. We had assumed that symptoms reporting would be associated with higher stress on the job as has been reported with low back pain in industrial workers. The majority of the other psychosocial variables added nothing to the modeling of who would be symptomatic. The workers' perceived stress and job satisfaction were not associated with higher symptom reporting. Workers with higher job security may have felt freer to report symptoms without jeopardizing their jobs but this is contrary to our original hypothesis.

Workers with a more profound abnormality of the median nerve, i.e., a more prolonged evoked response compared to the ulnar nerve in the same hand, did demon- strate a trend toward reporting more symptoms than workers with only a mild abnormality of the median nerve; the significance level was borderline. This was not a significant factor in the logistic regression models.

Although the number of active workers in the study with a history of diabetes was small (14 of 184), most of these workers with diabetes did not report symptoms (79\%). It is not surprising that workers with diabetes had prolonged median latencies. This has been reported many times and likely represents a mild underlying peripheral neuropathy where the median nerve is at higher risk of local compression [Albers et al., 1996]. The finding that the diabetic workers in our study are less likely to report symptoms probably reflects a mild peripheral neuropathy where their symptoms are masked secondary to their diabetic neuropathy.

The physiologic explanation of the variable symptom reporting despite prolongation of the median nerve across the wrist is unclear. The electrophysiologic responses are quite stable and reproducible and reflect the physiologic health of the median nerve in the carpal tunnel [Kimura et al., 1983]. The slowing primarily represents a thinning of the myelin sheath and/or a decrease in the internode distance between the nodes of Ranvier. Both changes are consistent with damage to the median nerve due to local compression. Under experimental conditions, acute compression causes transient conduction block that is also associated with reports of symptoms such as numbness and tingling in digits 1-4 in the hand [Gelberman et al., 1981]. We do not know how symptoms are expressed if the process that results in demyelination occurs slowly; there may never be an associated acute conduction block.

We recently reported that asymptomatic workers with a documented median mononeuropathy had only a $10 \%$ likelihood of developing symptoms of CTS over the next 2 years [Werner et al., 1997]. The incidence rate of workers reporting new symptoms did not differ from age- and sex-matched controls who had normal nerve conduction studies of the median nerve. Thus, active workers with a prolonged median sensory latency across the wrist are not simply in a pre-clinical state and are not likely to develop symptoms. The nerve is not functioning optimally, but whether this represents a diseased state and should be treated is unknown. The data clearly suggest that symptoms potentially consistent with CTS have only a modest relationship to electrophysiologic measures of nerve function at the wrist. The present study is limited because it is cross-sectional and cannot answer many of the questions raised; a longitudinal study would be necessary to determine the incidence and natural history of median mononeuropathy among active workers.

In conclusion, this study demonstrates that a relatively high number of active workers have prolongation of the median nerve reaction time on cross-sectional screening, yet 
one-half of these workers are asymptomatic. Women are three times more likely than men to report symptoms among workers with a median mononeuropathy (when controlled for other factors). Additionally, workers required to use their hands at higher repetition rates are also more likely to report symptoms. Psychosocial variables and degree of electrophysiologic abnormality are not helpful in differentiating the two groups.

\section{ACKNOWLEDGMENTS}

This research was supported, in part, by grant RO1OH02941-01 from the National Institute for Occupational Safety and Health. Its contents are solely the responsibility of the authors and do not necessarily represent the official views of the National Institute for Occupational Safety and Health.

\section{REFERENCES}

Albers JW Brown MB, Sima AA, Greene DA (1996): Frequency of median mononeuropathy in patients with mild diabetic neuropathy in the early diabetes intervention trial (EDIT. Tolrestat Study Group for Edit (Early Diabetes Intervention Trial. Muscle Nerve 19:140-146.

Anderson JV, Rafferty AP (1992): Overweight. In “Health Risk Behaviors1991.” Lansing, MI: Michigan Department of Public Health.

Franklin GM, Haug J, Heyer N, Checkoway H, Peck N (1991): Occupational carpal tunnel syndrome in Washington State, 1984-1988. Am J Public Health 82:741-746.

Franzblau A, Werner RA, Valle J, Johnston E (1993): Workplace surveil- lance for carpal tunnel syndrome: A comparison of methods. J Occup Rehabil 3:1-14.

Franzblau A, Werner RA, Albers JW, Olinski D, Johnston E (1994): Workplace surveillance for carpal tunnel syndrome using hand diagrams. J Occup Rehabil 4:185-198.

Gelberman RC, Hergenroeder PT, Hargens AR, Lundborg GN, Akeson WH (1981): The carpal tunnel syndrome: A study of carpal canal pressure. J Bone Joint Surg 63A:380-383.

Hanrahan LP Higgins D Anderson H Haskins L Tai S (1991): Project SENSOR: Wisconsin surveillance of occupational carpal tunnel syndrome. Wisc Med J 90:80-83.

Jackson D, Clifford JC (1989): Electrodiagnosis of mild carpal tunnel syndrome. Arch Phys Med Rehabil 70:1999-2004.

Karasek R (1985): “Job Content Questionnaire and User's Guide.” revision 1.1. Lowell, MA: University of Massachusetts.

Kimura J (1983): "Electrodiagnosis in Diseases of Nerve and Muscle: Principles and Practice." Philadelphia: FA Davis.

Latko W, Armstrong TJ, Foulke JA, Herrin GD, Rabourn RA, Ulin SS (1997): Development and evaluation of an observational method for assessing repetition in hand tasks. Am Ind Hyg Assoc J 58:278-285.

Redmond MD, Rivner MH (1988): False positive electrodiagnostic tests in carpal tunnel syndrome. Muscle Nerve 11:511-518.

StataCorp (1995): “Statistical Software: Release 4.0." College Station, TX: Stata Corporation.

Stock SR (1991): Workplace ergonomic factors and development of musculoskeletal disorders of the neck and upper limbs: A meta-analysis Am J Ind Med 19:87-107.

Werner RA, Franzblau A, Albers JW, Buchele H, Armstrong TJ (1997): Use of screening nerve conduction studies for predicting future carpal tunnel syndrome. Occup Environ Med 54:96-100. 